\title{
Análise de Investimento na Atividade Avícola com Base no Modelo Estocástico
}

\author{
Investment Analysis on Poultry Activity Based on Stochastic Model
}

\author{
Fernanda Eggers ${ }^{\mathrm{a}}$; Alexandre André Feil*b \\ ${ }^{a}$ Universidade do Vale do Taquari. RS, Brasil. \\ bUniversidade do Vale do Taquari, Programa de Pós-Graduação Stricto Sensu em Sistemas Ambientais Sustentáveis. RS, Brasil. \\ *E-mail: alexandre.feil1@gmail.com
}

\begin{abstract}
Resumo
O modelo de análise de investimento mais utilizado é a tradicional (determinística), porém possui a limitação de não incorporar os riscos endógenos e exógenos. Sendo assim, este estudo objetiva realizar uma análise comparativa entre a análise de investimento no setor avícola pelo método determinístico e estocástico. A metodologia empregada é qualiquantitativa, descritiva e o estudo de caso, sendo que a obtenção dos dados ocorreu por meio de entrevista estruturada e pesquisa documental primária. Os resultados revelam que a análise determinística sugere que o investimento é inviável, em função da VPL $<0$ e a TIR $<$ TMA. A análise estocástica do investimento, por intermédio do software @Risk ao considerar os riscos que podem interferir no setor avícola, sugere que há uma probabilidade de $44,43 \%$ do VPL $\geq 0$ e uma probabilidade de $40,9 \%$ da TIR $\geq$ TMA. A análise estocástica não exclui, mas abrange a análise determinista, nesse sentido, a estocástica apresenta as informações e dados com maior consistência e assertividade. Conclui-se que a análise estocástica fortalece a decisão sobre o investimento, pois ao incluir os riscos e gerar cenários apresenta o percentual de chance do investimento ser viável ou inviável.
\end{abstract}

Palavras-chave: Análise de Viabilidade. Avicultura. Riscos e Incertezas.

\begin{abstract}
The investment analysis model used is the traditional (deterministic), but has the limitation of not incorporating endogenous and exogenous risks. Therefore, this study aims to perform a comparative analysis between the investment analysis in the poultry sector for deterministic and stochastic method. The methodology used is quantitative, descriptive and case study and the data were collected through structured interview and documentary research. The results reveal that the deterministic analysis suggests that investment is infeasible due to the NPV $<0$ and the $I R R<T M A$. Stochastic analysis of investment through the @Risk software to consider risks that may interfere in the poultry sector, suggests that there is a likelihood of $44.43 \% N P V \geq 0$ and a likelihood of $40.9 \%$ of the IRR $\geq T M A$. Stochastic analysis does not exclude, but covers the deterministic analysis, the stochastic exhibits the information and data with greater consistency and assertiveness. It isconcluded that the stochastic analysis strengthens the decision on investment, because upon including the risks and generating scenarios presents the percentage chance of investment as feasible or infeasible.
\end{abstract}

Keywords: Feasibility Analysis. Poultry Farming. Risks and Uncertainties.

\section{Introdução}

A atividade agropecuária gera emprego e renda a um número expressivo de pessoas, contribuindo em nível global para o desenvolvimento social e econômico. No Brasil, as condições climáticas e extensão territorial favorecem a agricultura, a pecuária e o agronegócio.

O agronegócio, em especial, da pequena propriedade rural, é relevante à economia brasileira e a tendência é o crescimento da produção de alimentos, sendo assim, exige uma gestão eficaz (HOFER et al., 2011). Este crescimento e a competitividade e concorrência do mercado ampliaram os investimentos e consigo a análise da viabilidade econômica (SOUZA; SILVA JÚNIOR; SPIEGEL, 2017).

A análise de viabilidade de investimentos estima e analisa as perspectivas do desempenho financeiro (RODRIGUES; ROZENFELD, 2015). A análise tradicional (determinística) de investimentos pode ser realizada por diversas técnicas, métodos, convenções e critérios que podem ser utilizados no processo decisório, por exemplo, Valor Presente Líquido (VPL), Taxa Interna de Retorno (TIR) e payback (MARTINS et al., 2015).

A utilização das ferramentas tradicionais na análise da viabilidade de investimentos reduz a subjetividade da análise, porém tratam os riscos do negócio apenas pela taxa de atratividade do capital (SOUZA; SILVA JÚNIOR; SPIEGEL, 2017). A análise determinística se limita diante da dificuldade de modelar combinações de valores para diferentes dados de análise (MARTINS et al., 2015).

A decisão de investir se associa à incerteza e ao risco que podem afetar os fluxos de caixa (AMORIM; ROCHA, 2011). A mensuração do risco é essencial na utilização para comparação entre alternativas de investimento (LIMA JÚNIOR; ALDATZ, 2013). A análise de risco se utiliza de probabilidades associadas a um resultado determinístico para visualizar a ocorrência de certos eventos por meio de cenários (SOUZA; SILVA JÚNIOR; SPIEGEL, 2017). 
O Método Monte Carlo (MMC) é considerado um método probabilístico capaz de reduzir a incerteza, pois cria cenários a partir de inputs, ou seja, variáveis definidas como riscos esta análise é denominada de estocástica (VIANA; LEVINO; MOTA, 2008). Nesse contexto, este estudo objetiva analisar a viabilidade de investimento, considerando os riscos, na construção de dois aviários para produção de frango de corte.

O investimento, normalmente, ocorre com base em avaliações de viabilidade econômica do projeto, fundamentadas pelas técnicas tradicionais de análise e de orçamento de capital (VANDERLEI; CARMONA, 2008). Segundo os mesmos autores, essa análise desconsidera pelo menos duas decisões, que ocorrem na prática gerencial: o timing, que é a possibilidade de postergar o investimento versus a intempestividade da oportunidade (agora ou nunca); e a irreversibilidade do capital investido.

\section{Material e Métodos}

\subsection{Classificação da pesquisa}

O procedimento técnico utilizado foi um estudo de caso (GIL, 2012). Quanto ao objetivo a pesquisa se classifica em descritiva, uma vez que descreve características de populações ou fenômenos, podendo fazer relações entre variáveis e definir sua natureza (VERGARA, 2016).

\subsection{Unidade de análise}

O Brasil é considerado o segundo maior produtor de carne de frango global, na qual a produção é de 13,146 milhões de toneladas e seu consumo per capita médio é de 43,25kg em 2015 (ABPA, 2016). A avicultura no Estado do Rio Grande do Sul, em 2016, foi responsável pelo abate de 824 milhões de aves de corte (ASGAV, 2017). Nesse sentido se nota a importância da avicultura no Brasil e no Rio Grande do Sul, o que justifica a escolha da unidade de análise se centrar neste Estado.

A propriedade rural objeto deste estudo se situa no Rio Grande do Sul, Brasil, e possui 46 hectares e, desta área, cerca de 32 hectares são agricultáveis, já o restante corresponde a mata nativa, mata ciliar e áreas de banhado. Além disso, o relevo, em sua maior parte, é nivelado, o que é desejável para avicultura. A propriedade já possui dois aviários de madeira (Figura 1) e um de estrutura metálica, que alojam cerca de 60 mil frangos.

Figura 1 - Propriedade rural

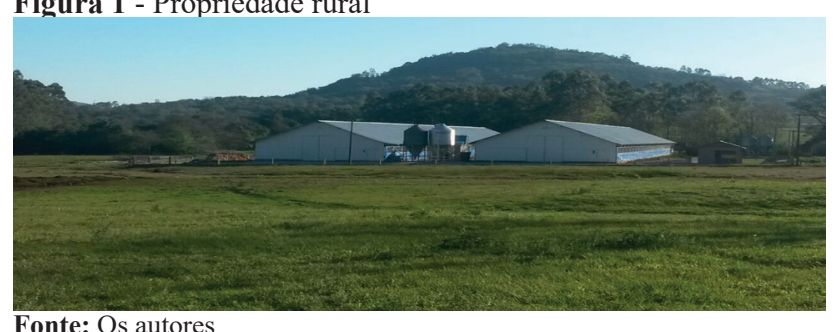

Fonte: Os autores

A construção desses novos aviários permite contribuições para que a propriedade passe a ter capacidade de alojamento para cerca de 100 mil frangos.

\subsection{Coleta e análise dos dados}

Os dados foram coletados diretamente com o empreendedor, a integradora, o banco financiador do investimento, a seguradora e a empresa de consultoria ambiental. As despesas e custos coletados por meio de entrevistas com o empreendedor, a integradora e a seguradora se relacionam ao pró-labore, energia elétrica, água, gás, manutenção, limpeza, cal, casca e serragem, desinfeção e seguro do aviário.

Os valores dos investimentos iniciais coletados com o empreendedor se centram na estrutura completa dos galpões, dos silos, dos comedouros, de bebedouro nipple, do cortinado completo, de ventiladores, de sistema de nebulização, de telas, de sistema elétrico com quadro de comando e máquina de cortina automática, campânulas, arco desinfecção, comedouro infantil, timer digital, madeira para o tablado, material e mão de obra (construção do escritório, composteira e cercamento), materiais e mão de obra para instalação elétrica, gerador de energia elétrica, caixas de água, entre outros. Essas informações foram coletadas por meio de pesquisa documental primária, em notas fiscais e orçamentos, em julho de 2017.

A coleta de dados com a integradora foi relacionada às receitas e aos lotes anuais que compreendem, a saber: a) Quantos lotes, por ano, cada produtor faz em média? b) Como funciona o pagamento dos lotes? O produtor recebe os pintos, a ração, os medicamentos que são descontados na entrega dos lotes? e c) Quais os resultados do produtor no último ano? Quantos dias tinham as aves alojadas em cada lote? Estas informações foram coletadas por e-mail entre julho de 2017 e agosto de 2017.

\subsection{Tratamento e análise dos dados coletados}

O tratamento dos dados se realizou por meio da tabulação, em planilhas eletrônicas, do Software Microsoft Office Excel 2013. As projeções do fluxo de caixa de 2017 a 2024 ocorreram observando os seguintes critérios: a) a projeção da receita foi de 3,90\% a.a., a partir de 2018, conforme previsto na OCDEFAO (2015); b) a projeção para as despesas foi de 4,50\% a.a., em 2018, conforme meta de inflação definida na Resolução $n^{\circ} 4499$ (BCB, 2016), de 4,25\% a.a. em 2019, de 4\% para o ano de 2020, conforme Resolução n 4582 (BCB, 2017), e de $4 \%$ a.a. em 2021 a 2027 em função de perspectivas futuras pelo governo brasileiro; c) a projeção do Fundo de Assistência ao Trabalhador Rural (FUNRURAL) foi de 1,5\% a.a. (1,20\% de contribuição à previdência, $0,10 \%$ ao RAT e $0,20 \%$ ao SENAR), de 2018 a 2027, em razão da Medida Provisória $n^{\circ}$ 793 de 2017.

Após esta projeção se montou o fluxo de caixa, que serviu como parâmetro para cálculo dos indicadores, tais como: VPL, TIR e payback, todos calculados com o auxílio do software Microsoft Office Excel 2013. Além disso, foi utilizado o software@Risk para cálculo do Método Monte Carlo, por meio de uma planilha 
universal que realiza previsões, simulações, além de fornecer informações quanto aos fatores de riscos (PALISADE, 2017).

A simulação pelo Método Monte Carlo é uma ferramenta relevante, pois através de probabilidades de resultados, melhora a qualidade da interpretação de dados para os tomadores de decisão, em ambientes de incerteza (SOUZA; SILVA JÚNIOR; SPIEGEL, 2017). Na atualidade existem vários softwares de simulação, que estão disponíveis no mercado, como o @Risk e o Crystal Ball (SAMANEZ, 2009).

\section{Resultados e Discussão}

\subsection{Descrição dos investimentos iniciais, gastos, receitas e projeções}

A construção dos aviários, objeto deste estudo, foi realizada entre fevereiro de 2017 e julho de 2017 e totalizou um investimento de R\$ 689.137,54. Esse valor é composto pelas instalações, equipamentos e despesas pré-operacionais (Quadro 1).

Quadro 1 - Investimento inicial

\begin{tabular}{|c|c|c|}
\hline Descrição & Quantidade/Medida/Especificação & Total (R\$) \\
\hline Estrutura dos galpões & 2 aviários de $96 \times 16$ de concreto & $294.000,00$ \\
\hline Silos 18 toneladas & 2 unidades & $12.000,00$ \\
\hline Comedouros e comedouros infantis & 1116 comedouros e 400 comedouros & $56.297,94$ \\
\hline Bebedouros Nipple & 5.208 bicos & $49.251,38$ \\
\hline Sistema de cortinado completo & Tela, cortinas e madeira para tablado & $89.006,00$ \\
\hline Ventiladores & 48 unidades & $21.000,00$ \\
\hline Sistema de nebulização & 140 bicos de alta vasão & $15.942,42$ \\
\hline Sistema elétrico** & 2 conjuntos & $33.971,81$ \\
\hline Campânulas & 30 unidades & $20.622,00$ \\
\hline Arco de desinfecção & 1 unidade & 850,00 \\
\hline Mão de obra*** & 1 conjunto & $17.036,65$ \\
\hline Material de construção* & 1 conjunto & $28.111,78$ \\
\hline Mesas e armário & Obrigatórios no escritório & 300,00 \\
\hline Portões, portas e janelas & 1 conjunto & $5.040,00$ \\
\hline Material para instalação elétrica & Cabos, conectores, tomadas, prendedores & 549,93 \\
\hline Mão de obra da instalação elétrica & 1 conjunto & 929,07 \\
\hline Lâmpadas utilizadas no aviário & 96 unidades & $1.178,00$ \\
\hline Gerador de Energia elétrica & 1 unidade & $15.500,00$ \\
\hline Caixas de água & 3 unidades & $8.022,00$ \\
\hline Triturador de cama de aviário & 1 unidade & $4.500,00$ \\
\hline Sistema de bomba de água & 1 conjunto & $3.400,00$ \\
\hline Horas de máquina & Enterrar canos de água & 550,00 \\
\hline Despesas pré-operacionais & Onde & Total (R\$) \\
\hline Licenças ambientais & Consultoria Ambiental & $1.764,94$ \\
\hline Horas de máquina da terraplenagem & Prefeitura Municipal & $3.613,62$ \\
\hline Saibro & Propriedade de vizinho & $4.500,00$ \\
\hline Projeto técnico do investimento & Emater & $1.200,00$ \\
\hline Total do investimento & & $689.137,54$ \\
\hline
\end{tabular}

Legenda: *(escritório, composteira e cerca) **com quadro de comando e máquina de cortina automática, ***para construção do escritório, composteira e cerca.

Fonte: Dados da pesquisa.

O valor do investimento, em partes foi financiado pelo Programa Nacional de Fortalecimento da Agricultura Familiar (PRONAF), através de três financiamentos bancários ${ }^{1}$, cujos valores são de R\$220.000,00², R\$ $180.000,00^{3}$ e R\$ 145.776,00 e, além disso, ainda haverá um complemento de recursos próprios. A escolha do Pronaf se justifica, pois financia projetos individuais ou coletivos a agricultores familiares e assentados da reforma agrária, e ainda, possui as menores taxas de juros de financiamento rurais (MDA, 2017).

O gasto relacionado aos "Valores da integradora" se refere a pododermatite (Quadro 2), uma infecção nas patas dos frangos, segundo Catalan et al. (2014). 
Quadro 2 - Gastos anuais operacionais

\begin{tabular}{|c|c|c|c|}
\hline Gastos & Valores & Gastos & Valores \\
\hline Salário do produtor & $\mathrm{R} \$ 11.244,00$ & Seguro obrigatório & $\mathrm{R} \$ 2.537,61$ \\
\hline Energia Elétrica & $\mathrm{R} \$ 3.250,00$ & Carregamento das aves & $\mathrm{R} \$ 16.784,56$ \\
\hline Aquecimento (gás) & $\mathrm{R} \$ 9.600,00$ & Despesas telefônicas & $\mathrm{R} \$ 100,00$ \\
\hline Manutenção & $\mathrm{R} \$ 1.300,00$ & Combustível & $\mathrm{R} \$ 240,00$ \\
\hline Casca e serragem & $\mathrm{R} \$ 6.500,00$ & Valores da integradora & $\mathrm{R} \$ 1.415,69$ \\
\hline Lavagem dos aviários & $\mathrm{R} \$ 768,00$ & $\mathrm{ITR}$ & $\mathrm{R} \$ 2,13$ \\
\hline Cal & $\mathrm{R} \$ 200,00$ & $\mathrm{INCRA}$ & $\mathrm{R} \$ 0,79$ \\
\hline Desinfecção do aviário & $\mathrm{R} \$ 1.500,00$ & & \\
\hline
\end{tabular}

Fonte: Dados da pesquisa.

A receita foi apurada com base nas informações da integradora, na qual cada integrador de frangos realiza, em média, seis lotes por ano (Quadro 3). A integradora fornece os pintos, os insumos e a medicação necessária à criação de frangos, descontando-os do valor pago pelo lote. A remuneração paga pela entrega das aves se baseia no índice de produção, que considera o peso médio do lote, conversão alimentar, idade do lote e viabilidade.

Quadro 3 - Histórico de receita e quantia de aves alojadas, em 2016

\begin{tabular}{|c|c|c|c|c|}
\hline Idade do Lote & R\$ por Ave & Total (R\$) & $\begin{array}{c}\text { Quantidade de Aves } \\
\text { Alojadas }\end{array}$ & $\begin{array}{c}\text { Quantidade de Aves } \\
\text { Abatidas }\end{array}$ \\
\hline 45 & 0,635 & $18.589,15$ & 30.000 machos & 29.270 \\
\hline 45 & 0,604 & $18.012,90$ & 30.500 machos & 29.829 \\
\hline 41 & 0,567 & $21.012,78$ & 37.500 fêmeas & 37.080 \\
\hline 42 & 0,618 & $22.833,59$ & 37.400 fêmeas & 36.930 \\
\hline 44 & 0,633 & $20.843,80$ & 33.600 fêmeas & 33.200 \\
\hline 40 & 0,677 & $20.283,24$ & 32.000 machos & 31.580 \\
\hline Total & & & 201.000 & 197.889 \\
\hline
\end{tabular}

Fonte: Dados da pesquisa.

$\mathrm{O}$ alojamento dos frangos ocorreu em aviários com dimensões de $108 \times 12$ e $104 \times 14$ metros, que totalizam 2.752 metros quadrados, e nesse espaço foram alojados, em média, 12,17 frangos por metro quadrado 4 (Quadro 3). Esta média utilizou como referência na projeção dos alojamentos nos aviários com dimensões de 96x16 metros. A mortalidade dos frangos apresentou a média de $1,55 \%{ }^{5}$ e a receita média do integrador foi de $\mathrm{R} \$ 0,66$ por ave (Quadro 3). Com base nestas informações foi elaborada a projeção do fluxo de caixa (Quadro 4).

Quadro 4 - Resumo da projeção do fluxo de caixa, de 2017 a 2027, em reais

\begin{tabular}{|c|c|c|c|c|c|c|c|c|c|c|c|}
\hline & 2017 & 2018 & 2019 & 2020 & 2021 & 2022 & 2023 & 2024 & 2025 & 2026 & 2027 \\
\hline Receitas operacionais & 48.647 & 151.633 & 157.546 & 163.691 & 170.074 & 176.707 & 183.599 & 190.759 & 198.199 & 205.929 & 213.960 \\
\hline$(=)$ Gastos operacionais & 23.933 & 61.425 & 64.024 & 67.231 & 69.240 & 72.006 & 74.882 & 78.640 & 80.984 & 84.219 & 87.583 \\
\hline Remuneração & 3.748 & 11.750 & 12.249 & 12.739 & 13.249 & 13.779 & 14.330 & 14.903 & 15.499 & 16.119 & 16.764 \\
\hline Energia, gás, manutenção & 4.717 & 14.787 & 15.415 & 16.032 & 16.673 & 17.340 & 18.034 & 18.755 & 19.505 & 20.285 & 21.097 \\
\hline $\begin{array}{l}\text { Casca, lavagem, cal, } \\
\text { desinfecção }\end{array}$ & 7.323 & 9.372 & 9.770 & 10.161 & 10.567 & 10.990 & 11.429 & 11.887 & 12.362 & 12.856 & 13.371 \\
\hline $\begin{array}{l}\text { Seguro, ITR, INCRA, } \\
\text { licenças. }\end{array}$ & 1.966 & 6.142 & 6.391 & 7.293 & 6.905 & 7.178 & 7.461 & 8.522 & 8.061 & 8.378 & 8.709 \\
\hline Carregamento & 6.067 & 19.019 & 19.828 & 20.621 & 21.446 & 22.303 & 23.195 & 24.123 & 25.088 & 26.092 & 27.135 \\
\hline Telefone, gasolina & 113 & 355 & 370 & 385 & 401 & 417 & 433 & 451 & 469 & 487 & 507 \\
\hline$(=)$ Gastos financeiros & 3.766 & 34.626 & 30.430 & 26.542 & 22.065 & 16.862 & 10.874 & 4.127 & 2.808 & 10.333 & 18.679 \\
\hline \begin{tabular}{|l} 
Juros pagos \\
\end{tabular} & - & 34.528 & 30.852 & 27.868 & 24.609 & 21.087 & 17.247 & 13.076 & 9.180 & 5.319 & 1.245 \\
\hline IOF & 2.516 & 362 & 334 & 288 & 226 & 142 & 36 & - & - & - & - \\
\hline Taxas e seguro & 1.250 & 1.306 & 1.362 & 1.416 & 1.473 & 1.532 & 1.593 & 1.657 & 1.723 & 1.792 & 1.864 \\
\hline Juros recebidos & - & 1.570 & 2.118 & 3.030 & 4.244 & 5.899 & 8.001 & 10.606 & 13.711 & 17.444 & 21.787 \\
\hline (=) Fluxo de caixa & 20.948 & 55.581 & 63.093 & 69.917 & 78.769 & 87.839 & 97.842 & 107.992 & 120.023 & 132.043 & 145.056 \\
\hline Saldo acumulado & 20.948 & 76.529 & 139.622 & 209.539 & 288.308 & 376.147 & 473.989 & 581.981 & 702.004 & 834.047 & 979.103 \\
\hline
\end{tabular}




\subsection{Análise de viabilidade pelo método tradicional}

O valor do VPL se apresenta negativo, ou seja, o fluxo de caixa não foi capaz de recuperar o valor investido (Quadro 5). Os estudos precedentes, a saber, Zanin et al. (2011) analisaram três investimentos distintos na produção de frango de corte em Santa Catarina, com projeção de 20 anos, e Bianchini (2014) avaliou a viabilidade da implantação de um aviário tipo Dark House $^{6}$ no Rio Grande do Sul (RS), com período de 12 anos, os resultados da VPL se apresentaram negativos e positivos, respectivamente. Portanto, os resultados revelam distintas perspectivas de viabilidade.

Quadro 5 - Indicadores de viabilidade

\begin{tabular}{|l|c|}
\hline VPL & -R\$ 205.273,68 \\
\hline Payback simples & 8,89 anos \\
\hline Payback descontado & - \\
\hline TIR & $5,14 \%$ \\
\hline TMA & $10,98 \%$ \\
\hline
\end{tabular}

Fonte: Dados da pesquisa.

O payback simples revela um período de 8,89 anos, considerando um total de 10 anos, já em Casanova (2014), em Marau, RS, o payback não foi viável dentro do período da projeção de 5 anos e em Gabiatti (2016), no Vale do Taquari, RS, o payback médio foi de 9,5 anos em um total de 10 anos. Sendo assim, percebe-se que o período de payback médio pode ser em torno de 9 anos, ou seja, a projeção deve ser superior de 10 anos para que haja viabilidade do investimento.

Este estudo revela que a TIR < TMA sugerindo que o investimento é inviável em função da taxa de retorno (Quadro 5). Gabiatti (2016) também obteve esta conclusão (TIR =6,10 e TMA =17,7), já Bianchini (2014) obteve a TIR > TMA com resultados de $15,8 \%$ e $12 \%$, respectivamente. Neste indicador, os resultados também se revelam ambíguos.

A análise conjunta dos indicadores revela que o investimento é inviável (Quadro 5), o que corrobora com Zanin et al. (2011) e Gabiatti (2016) e contraria Bianchini (2014) e Casanova (2014). O fato dessas ambiguidades pode ser explicado pelo valor do investimento inicial, o valor pago pela integradora, pelas distintas áreas geográficas que apresentam variações climáticas intervenientes no processo de eficiência produtiva, o valor gasto em mão de obra na construção do empreendimento, as diferentes taxas de TMA utilizadas, o período da projeção do fluxo de caixa, a metragem do galpão, a quantidade de pintos alojados por metro quadrado, exigências das integradoras podem elevar o gasto na estrutura física e manejo dos frangos, entre outros.

\subsection{Análise de viabilidade pelo método estocástico}

Os parâmetros da média e do desvio padrão de cada um dos inputs incertos foram determinados com base no fluxo de caixa de 2018 a 2027 (Quadro 6).
Quadro 6 - Parâmetros de distribuição para a aplicação do Monte Carlo

\begin{tabular}{|l|c|r|r|}
\hline \multicolumn{1}{|c|}{$\begin{array}{c}\text { Inputs } \\
\text { incertos }\end{array}$} & Distribuição & Média & \multicolumn{1}{c|}{$\begin{array}{c}\text { Desvio } \\
\text { padrão }\end{array}$} \\
\hline $\begin{array}{l}\text { Custo do } \\
\text { investimento }\end{array}$ & Normal & $\mathrm{R} \$ 689.137,54$ & $\mathrm{R} \$ 30.000,00$ \\
\hline Receita & Normal & $\mathrm{R} \$ 181.200,00$ & $\mathrm{R} \$ 21.000,00$ \\
\hline $\begin{array}{l}\text { Custo fixo } \\
\text { anual }\end{array}$ & Normal & $\mathrm{R} \$ 63.274,00$ & $\mathrm{R} \$ 3.000,00$ \\
\hline $\begin{array}{l}\text { Taxa de } \\
\text { crescimento } \\
\text { da receita }\end{array}$ & Normal & $3,90 \%$ & $3,00 \%$ \\
\hline Custo variável & Normal & $12,00 \%$ & $10,00 \%$ \\
\hline
\end{tabular}

Fonte: Dados da pesquisa.

A inserção desses dados no Software@risk com a programação de geração de 5.000 cenários obteve os resultados da VPL (Gráfico 1).

Gráfico 1 - Valor Presente Líquido

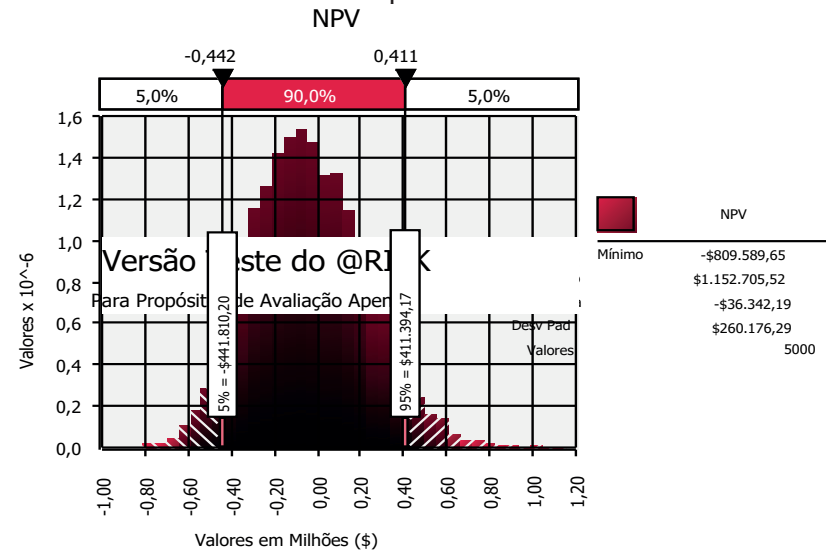

Fonte: Dados da pesquisa.

A VPL pelo método estocástico se concentra em 100\% nos cenários entre $-809.589,65$ e 1.152.705,52, além disso, notase no Gráfico 2 que a VPL tem uma probabilidade de $90 \%$ de estar entre $-441.810,20$ a 411.394,17. Com base nisso se apura a probabilidade da VPL $\geq 0,00$, conforme segue:

$$
\mathrm{Z}=(\mathrm{x}-\mathrm{u}) / \sigma=(0-(-36.342,19)) / 260.176,26=0,139688
$$

A verificação do valor na distribuição da Tabela $Z$ constata o valor de 0,5557 , e este é a base para cálculo da probabilidade de viabilidade do $\mathrm{VPL} \geq 0$ :

$$
\mathrm{p}(\mathrm{Z} \geq 0,139688)=1,000-0,5557=0,4443
$$

O significado do valor 0,4443 é que há uma probabilidade de $44,43 \%$ para que o projeto alcance uma VPL $\geq 0$ no período de 10 anos. Diante disso se nota que a viabilidade do investimento contém um risco significativo em relação ao VPL.

A apuração da TIR, por meio do Software@Risk, também teve como base as informações dos inputs incertos (Gráfico 2).

6 Galpão que possui luminosidade e ventilação artificial e totalmente controlada. 
Gráfico 2 - Taxa interna de retorno

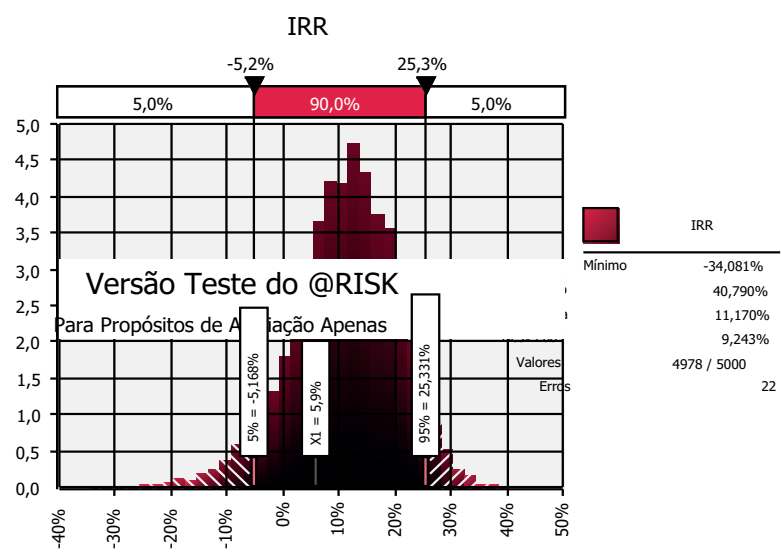

Fonte: Dados da pesquisa.

A TIR pelo método estocástico se concentra em 100\% dos cenários entre $-34,1 \%$ e 40,8\%, além disso, se nota no Gráfico 2 , que a TIR tem uma probabilidade de $90 \%$ de estar entre $-5,2 \%$ e $25,3 \%$. Com base nisso se apura a probabilidade do valor da TIR $\geq$ TMA, conforme segue:

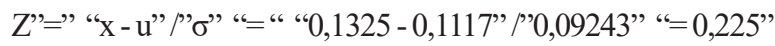

$A$ verificação na Tabela $Z$ revela a base para cálculo da probabilidade de viabilidade da TIR $\geq$ TMA:

$$
\mathrm{p}(\mathrm{Z} \geq 0,225)=1,000-0,5910=0,409
$$

O significado do valor 0,409 é que há uma probabilidade de $40,9 \%$ para que o projeto alcance uma TIR $\geq$ TMA no período de 10 anos. Diante disso se nota que a viabilidade do investimento contém um risco significativo também em relação à TIR. Após a apuração dos cálculos pelo método tradicional e estocástico na sequência são analisados estes resultados.

A decisão relativa ao investimento sugere que é inviável sob a perspectiva tradicional (VPL, Payback, TIR e TMA) e sob a perspectiva estocástica (VPL e TIR) tem cerca de $40 \%$ de probabilidade de ser viável. Nesse sentido, a tradicional é complementada com as informações geradas pela estocástica, que aponta a probabilidade do investimento ser viável ou inviável. Essa informação, dependendo do perfil do investidor e do risco que o mesmo deseja assumir, pode ser o diferencial quanto a decisão de considerar o investimento (in)viável. Viana, Levino e Mota (2008) corroboram com esta reflexão, quando enfatizam que a análise tradicional pode substituir a estocástica, pois há uma quantificação e possível redução do nível de riscos.

As tecnologias avançadas de análise de investimentos, por meio de softwares, contribuem pelo fato da capacidade de manipulação de elevada quantidade de informações, dinâmica econômica, inclusão de inputs relacionados aos riscos, uso de estatística e probabilidade robusta, ambiente financeiro complexo, instável e rápido, entre outros. Esta afirmação também é defendida por Fonseca e Bruni (2010), Souza, Silva Júnior e Spiegel (2017) e Rogers, Rogers e Ribeiro (2006).

\section{Conclusão}

A análise de investimento mais difundida é a determinística (tradicional), baseada em dados precisos e, em razão disso, sofre limitações relacionadas ao fator da tomada de decisão. Nesse viés, este estudo objetivou a análise da viabilidade de investimento, levando em consideração os riscos e as incertezas, na construção de dois aviários para produção de frango de corte.

Os resultados revelam que o VPL, por intermédio do método determinístico, é de $\mathrm{R} \$-205.273,68$. O payback simples foi de 8,89 anos, e o payback descontado não pode ser calculado, visto que ultrapassa o período de projeção do fluxo de caixa deste estudo. Já a TIR apresentou taxa de 5,14\% e a TMA considerada foi de 10,98\%. Esses indicadores sinalizam que o investimento é inviável dentro do período de análise.

O método estocástico aponta que há uma probabilidade de $44,43 \%$ para que o projeto alcance uma VPL $\geq 0$ e $40,9 \%$ para que o projeto alcance uma TIR $\geq$ TMA, em um período de 10 anos, considerando os riscos envolvidos no processo. Percebese, portanto, que ao contrário do método determinístico, que considerou o empreendimento inviável, quando analisado pelo estocástico, o investimento apresenta cerca de $40 \%$ de viabilidade. Portanto, o método baseado em probabilidade apresenta um diagnóstico mais realístico do que o método tradicional. Dessa forma, permite ao investidor conhecer, com uma maior exatidão, os riscos do investimento.

Conclui-se que a análise estocástica possui potencial de assertividade, pois essa trata as variáveis (projeção das receitas e dos gastos), não como valores fixos, como ocorre na análise determinística, mas como um valor aleatório que respeita uma distribuição de probabilidade estipulada pelo analista. Essa combinação de cenários (otimista, realista e pessimista), em uma única análise, proporciona que o investidor obtenha uma visão mais ampla dos cenários do investimento e avalie, com maior precisão, se está disposto a assumir os riscos do projeto.

\section{Referências}

AMORIM, D.E.; ROCHA, F.S. Análise de projetos de investimento sob incerteza: uma aplicação de opções reais. Techoje, 2011. Disponível em: http://www.techoje.com.br/site/ techoje/categoria/detalhe_artigo/1101. Acesso em: 13 jan. 2018.

ABPA - Associação Brasileira de Proteína Animal. Produção de carne de frango totaliza 13,146 milhões de toneladas em 2015. 2016. Disponível em: http://abpa-br.com.br/noticia/producaode-carne-de-frango-totaliza-13146-milhoes-de-toneladasem-2015-1545. Acesso em: 16 fev. 2018.

ASGAV - Associação Gaúcha de Avicultura. Dados da avicultura Brasil: Relatórios Anuais ABPA - Período de 2011 à 2016. 2017. Disponível em: http://www.asgav.com.br/_files/view.php/load/ pasta/5/579e23aac313e.pdf. Acesso em: 15 jan. 2018.

BCB - Banco Central do Brasil. Resolução $n^{\circ} 4499$, de 30 de junho de 2016. Fixa a meta para a inflação e seu intervalo de tolerância para o ano de 2018. 2016. Disponível em: http://www.bcb.gov.br/ pre/normativos/busca/download Normativo.asp?arquivo=/Lists/ Normativos/Attachments/50222/Res_4499_v1_O.pdf. Acesso em: 1 fev. 2018. 
BCB - Banco Central do Brasil. Resolução $n^{\circ} 4582$, de 29 de junho de 2017. Fixa a meta para a inflação e seu intervalo de tolerância para os anos de 2019 e 2020. 2017. Disponível em: http://www.bcb.gov.br/pre/normativos/busca/download Normativo.asp?arquivo=/Lists/ Normativos/Attachments/50402/ Res 4582 v1 O.pdf. Acesso em: 1 Fev. 2018.

BEUREN, I.M. Como elaborar trabalhos monográficos em contabilidade: teoria e prática. São Paulo: Atlas, 2013.

BIANCHINI, B.J. Estudo de viabilidade financeira na implantação de um aviário modelo dark house em uma propriedade rural no município de Nova Bréscia. Lajeado: Centro Universitário Univates, 2014.

CASANOVA, T. Estudo de viabilidade para ampliação de um empreendimento avícola no município de Marau. Passo Fundo: Universidade de Passo Fundo, Passo Fundo, 2014.

CATALAN, A.A.S. et al. Lesão por pododermatite em frangos de corte alojados em diferentes densidades. Campinas: Fundação APINCO de Ciência e Tecnologia Avícolas, 2014.

FONSECA, Y.D.; BRUNI, A.L. Técnicas de avaliação de investimentos: uma breve revisão da literatura. 2010. Disponível em: http://www.infinitaweb.com.br/albruni/ artigos/a0303 CAR_AvalInvest.pdf. Acesso em: 27 jan. 2018.

GABIATTI, J. Análise da viabilidade de investimento pelo modelo tradicional e modelo crystal ball em atividade avícola. 2016. Lajeado: Centro Universitário Univates, 2016.

GIL, A.C. Métodos e técnicas de pesquisa social. São Paulo: Atlas, 2012.

HOFER, E. et al. A relevância do controle contábil para o desenvolvimento do agronegócio em pequenas e médias propriedades rurais. Rev. Contab. Control., v.3, n.1, p.27-42, 2011. doi 10.5380/rcc.v3i1.21490.

LIMA JÚNIOR, M.P.; ALDATZ, R.J. Análise de investimento do segmento de transporte em condições de incerteza e risco. Rev. Amb. Contabil., v.5, n.1, p.224-240, 2013.

MARTINS, E.F. et al. Estudo Estocástico de projeto: uma análise de sensibilidade com aplicação da simulação de Monte Carlo. Rev. Espacios, v.36, n.17, 2015.

OCDE-FAO - Organização para a Cooperação e Desenvolvimento Econômico; Organização das Nações Unidas para a Alimentação e Agricultura. Perspectivas Agrícolas 2015-2024. 2015. Disponível em: http://www.fao.org.br/download/PA20142015CB.pdf. Acesso em: 20 fev. 2018.

PALISADE.Palisade@Risk.2017. Disponível em: http://www. palisade-br.com/risk/. Acesso em: 6 fev. 2018.

RODRIGUES, K.F.C.; ROZENFELD, H. Análise de viabilidade econômica. 2015. Disponível em: http://www. portaldeconhecimentos .org.br/index.php/por/content/ download/ 11664/114678/file/Analise\%20de\%20viabilidade\%20 econ $\%$ C $3 \%$ B 4 mica portal $\% 20$ de $\% 20$ conhecimentos.pdf. Acesso em: 6 fev. 2018.

ROGERS, D.; ROGERS, P.; RIBEIRO, K.C.S. Análise de alternativas de investimento considerando os efeitos do risco: simulação por Hipercubo Latino. In: CONGRESSO BRASILEIRO DE CUSTOS-ABC, Belo Horizonte, Minas Gerais. Anais [...] Belo Horizonte, Minas Gerais. 2006.

SAMANEZ, C.P. Engenharia econômica. São Paulo: Pearson Prentice Hall, 2009.

SOUSA, A.F. Avaliação de investimentos: uma abordagem prática. São Paulo: Saraiva, 2007.

SOUZA, R.J.; SILVA JÚNIOR, D.S.; SPIEGEL, T. Para além do VPL e da TIR: Aplicação de métodos analíticos estocásticos à avaliação de projetos-estudo de cenários de negócios do mercado de cervejas artesanais. Rev. Contab. Mest. Ciênc. Contáb. UERJ, v.21, n.3, p.74-94, 2017.

VANDERLEI, L.O.O.; CARMONA, C.U.M. A teoria das opções reais como ferramental para avaliação de projetos de investimentos sob incertezas. $J$. Adm. Sci., v.14, n.1, p.122-139, 2008.

VERGARA, S.C. Projetos e relatórios de pesquisa em administração. São Paulo: Atlas, 2016.

VIANA, J.C.; LEVINO, N.A.; MOTA, C.M.M. Simulação de Monte Carlo auxiliando a análise de viabilidade econômica de projetos. In: CONGRESSO NACIONAL DE EXCELÊNCIA EM GESTÃO. Niteroi, Rio de Janeiro. Anais ... Niteroi, Rio de Janeiro, 2008.

ZANIN, A. et al. Viabilidade econômica e financeira da atividade avícola: estudo de casos em propriedades rurais. In: CONGRESSO UFSC DE CONTROLADORIA E FINANÇAS Florianópolis, Santa Catarina. Anais... Florianópolis, Santa Catarina, 2011 